\title{
Phytofabrication of silver nanoparticles using Myriostachya wightiana as a novel bioresource, and evaluation of their biological activities
}

\author{
Varahalarao Vadlapudi ${ }^{1 *}$, Ramars Amanchy ${ }^{1}$ \\ ${ }^{1}$ Biology Division, CSIR-Indian Institute of Chemical Technology (IICT), Uppal Road, Tarnaka, Hyderabad - \\ 500007, India.
}

\begin{abstract}
Nanobiotechnology deals with the properties of nanomaterials and their potential uses. Here we report for the first time novel, cost-effective and eco-friendly method for the rapid green synthesis of silver nanoparticles (AgNPs) using leaf extracts of Myriostachya wightiana. The growth of silver nanoparticles was monitored by UV-vis spectroscopy complemented by Zeta potential, dynamic light scattering technique (DLS), Fouriertransform infrared spectroscopy (FTIR), Transmission electron microscope (TEM) and X-ray diffraction (XRD). The surface plasmon resonance (SPR) band found at $434 \mathrm{~nm}$ confirmed the reduction of $\mathrm{AgNO}_{3}$ to $\mathrm{AgNPs}$. TEM micrographs revealed that AgNPs are irregular in shape with the size range from 15-65 $\mathrm{nm}$. The functional groups responsible for bio-reduction of silver nitrate into silver were analyzed by FTIR and confirmed by X-ray photoelectron spectrum (XPS). Further these biogenic AgNP were evaluated for insecticidal activities against stored product pests, Tribolium castaneum (Flour beetle), Rhyzopertha dominica (F.)(Lesser grain borer) and Sitophilus oryzae L (Rice weevil). The fabricated AgNPs showed moderate activity on stored pests and strong antibacterial activity with varying degrees against Xanthomonas campestris and Ralstonia solanacearum as evidenced by their zone of inhibition at all concentrations. Hence, these AgNP can be used as control agents against agricultural pests and pathogens in future.
\end{abstract}

Key word: Nanobiotechnology, Myriostachya wightiana, Tribolium castaneum, Xanthomonas campestris

\footnotetext{
*Author for correspondence: vvraophd@gmail.com
} 


\section{INTRODUCTION}

Nanotechnology is an emerging field in the area of interdisciplinary research, especially in plant biotechnology. Nanoparticles possess very high surface to volume ratio. Silver, Aluminum, Gold, Zinc, Carbon, Titanium, Palladium, Iron and Copper have been routinely used for the synthesis of NPs since more than decade. Nanosilver has many important applications in textiles, home water purification systems, catalysis, imaging, drug delivery, biosensing, cosmetics, electronics, household appliances, nano device fabrication and in medicine $\left[{ }^{1,2,3,4}\right]$. The antibacterial effects of Ag salts have been reported since ancient times. Silver nanoparticles are particularly attractive because of their remarkable physicochemical properties. Production of NPs can be achieved through different methods, among which chemical approaches are the most popular but potentially toxic to humans. It is now established that the plants and plant materials act as excellent reducing agents that catalyze bulk materials into nano form.Biological methods of nanoparticles production are regarded as safe, cost-effective, sustainable and environment friendly. Several biological systems including bacteria, fungi, algae and plants have been used in the synthesis of AgNPs $\left[{ }^{5,6,7,8}\right]$. Nanoparticles produced by these methods have protective bio-capping around them, rendering the particles to be stable with no aggregation $\left[{ }^{9}\right]$. Synthesis of inorganic nanoparticles by biological systems makes nanoparticles more biocompatible and environmentally benign $\left[{ }^{10}\right]$. The rate of reduction of metal ions using plant extracts have been found to be much faster as compared to micro-organisms $\left[{ }^{11}\right]$.

Pests are very important antagonist against agricultural production systems and urgently we need to develop green and safer alternative methods of controlling them.NPs are showing promise in different fields of agricultural biotechnologyand helping in production of newer pesticides, insecticides and insect repellents. Therefore, extensive studies are being carried out to screen biogenic NPs for pesticidal property.

With increasing resistance of bacteria against the antibiotics in agriculture has become essential to search for alternative preventing measures. Therefore, there is an urgent need to evaluate potential NPs for antimicrobial activity against various phytopathogens. Silver nanoparticles (AgNPs) have been known for their inhibitory and bactericidal effect. Silver is also known to exhibit an oligodynamic effect because of its ability to exert bactericidal activity even at minimum concentrations. Many studies are restricted to usage of mangroves because they grow in very harsh environment. Marine environmental conditions are extremely different from terrestrial ones; it is surmised that mangroves have diverse group of compounds that aid in tolerating salinity and other types of stress conditions.

Myriostachya wightiana (Nees ex Steud.) Hook. f. belonging to the family Poaceae, is a perennial salt marsh grass grows along the muddy creeks and channels in inter-tidal mangrove swamps of a coringa Kakinada, Andhra Pradesh, India. This plant commonly used as fodder grass and thatching material. It plays a vital role in soil conservation, phytoremediation, provides habitat for fishes and other organisms and livelihood to local rural people in and around mangrove areas. $\left[{ }^{12}\right]$ Evaluated crude extracts of this plant against selected phytopathogens. Xanthomonas campestris pv. campestris is responsible for black rot disease on crucifers viz: mustard, cabbage and cauliflower, which is a seed born, vascular disease and bacterial wilt caused by $R$. solanacearum is a serious disease in the production of tomatoes and many other crops in tropical, subtropical and warm temperate regions of the world $\left[{ }^{13}\right]$. 
Phytofabrication of silver nanoparticles using Myriostachya wightiana as a novel bioresource, and evaluation of their biological activities

The present study investigated the synthesis of silver nanoparticles with the phytoreduction method using aqueous extract of $M$. wightiana and evaluated for their insecticidal and antibacterial activity against $X$. campestris and $R$. solanacearum.

\section{MATERIALS AND METHODS}

\section{Plant material and chemicals}

Marine plant M. wightiana (Poaceae) was collected from Pedavalasala village (Thallarevu Mandal), $10 \mathrm{~km}$ fromcoringa mangrove forest, which is near to Yanam, Kakinada, Andhra Pradesh, India during July and August 2015. Silver nitrate $\left(\mathrm{AgNO}_{3}\right)$ purchased from (Sigma-Aldrich, USA), Muller-Hinton agar (MHA) medium purchased from (SRL Laboratories Limited, Mumbai). Chloramphenicol from (Himedia Laboratories Limited, Mumbai).

\section{Test organisms}

The stored product pests, Tribolium castaneum and Rhyzopertha dominica were reared in $1 \mathrm{~kg}$ jars containing dry seeds of Jowar (Sorghum vulgare L.) whereas, Sitophilus oryzae on whole wheat (Triticum aestivum L.). All insect cultures were maintained at $28 \pm 2^{\circ} \mathrm{C}$ and $65 \pm 5 \%$ relative humidity. Ralstonia solanacearum and Xanthomonas campestris pv. campestris are procured from the National Bureau of Agriculturally Important Microorganisms Culture Collection (NAIMCC), Mau Nath Bhanjan, U.P. (India).

\section{Biosynthesis and purification of AgNPs}

The marine plant $M$. wightiana was washed thoroughly with double distilled water and finely cut into small pieces. Then finely cut plant materials $(5 \mathrm{~g})$ were transferred to $250 \mathrm{~mL}$ Erlenmeyer flasks containing $100 \mathrm{~mL}$ of de-ionized water. Mixed thoroughly, boiled for $5 \mathrm{~min}$ and filtered through Whatman No.1 filter paper. For synthesis of Ag nanoparticles, $10 \mathrm{~mL}$ of leaf broth was mixed with 190 $\mathrm{mL}$ of aqueous $\mathrm{AgNO}_{3}$ solution $(1 \mathrm{mM})$ and further exposed directly to sunlight for irradiation from 11 a.m. to 2 p.m. under clear sky condition. Reduction occured slowly and colour was change to brown. The AgNPs were obtained by centrifuging at $12,000 \mathrm{rpm}$ for $10 \mathrm{~min}$, washed three times with deionized water to remove any water soluble material and sonicated to prevent aggregation and further use hot air over to remove water content.

\section{Characterization of the Silver Nanoparticles (AgNPs)}

To characterize AgNPs, the absorption spectra of the samples were taken 300 to $800 \mathrm{~nm}$ using a UV-vis spectrophotometer (Spectramax M3 molecular devices) operating at the resolution of $1 \mathrm{~nm}$. The particle size distributions (PSD) and Zeta potential of the synthesized AgNPs were determined by nanoparticle analyzer (Nano ZS90 instrument, Malvern, UK), Transmission electron microscope (TEM) was performed on a FEI Tecnai F12 (Philips Electron Optics, Holland) instrument operated at $100 \mathrm{kV}$, X-ray diffraction (XRD) patterns were recorded on Bruker D-8 Advance power XRD, FT-IR measurements was carried out using Thermo Nicolet Nexus 670 spectrometer in the diffuse reflectance mode at a resolution of $4 \mathrm{~cm}^{-1}$ in $\mathrm{KBr}$ pellets and X-ray Phototelectron Spectroscopic (XPS) studies carried out using KRATOS AXIS 165, Shimadzu Group, UK. 


\section{Contact toxicity against stored grain pests}

The insecticidal activity of biosynthesized and synthetic nano silver against adults of three stored product insects was evaluated by direct contact application assay $\left[{ }^{14}\right]$.The nano silver were prepared in distilled water at different concentrations (50, 100 and $150 \mu \mathrm{g} / 100 \mu \mathrm{L}$ ) and applied on filter papers (Whatman No. 1, cut into $5 \mathrm{~cm}$ ${ }^{2}$ pieces) separately. Distilled water was allowed to evaporate for 10-15 min prior to introduction of insects. Then each paper (dried) was placed at the bottom of a Petri plates $(5.5 \mathrm{~cm}$ diameter $\times 1.2 \mathrm{~cm})$ and 10 adults each of $T$. castaneum, $R$. dominica, and $S$. oryzae were placed in each petri plates and covered with a lid. The inner side of the lid was coated with Vaseline to prevent insect staying on lid. Controls received $100 \mu \mathrm{L}$ distilled water alone. There were a total of 15 replicates per treatment and the treatments were done on three different days $(\mathrm{N}=45)$. Mortality percentages were measured after exposure for 24,48 , and $72 \mathrm{hrs}$ of treatment.

\section{Antibacterial assay by Agar well diffusion method}

AgNPs synthesized using M. wightiana were tested for antibacterial activity by agar well diffusion method according to $\left[{ }^{15}\right]$ with minor modifications against $X$. campestris and $R$. solanacearum. A single colony of test strains $X$. campestris and $R$. solanacearum were grown over night in the nutrient broth on a rotary shaker $(200 \mathrm{rpm})$ at $35^{\circ} \mathrm{C}$ for $24 \mathrm{~h}$. Then a loop full of bacterial culture was swapped homogeneously onto Muller- Hinton agar (MHA) medium plates using sterile cotton swabs. Well of $6 \mathrm{~mm}$ diameter were prepared using gel puncture. Different concentrations of AgNPs $(25,50,75,100$ and $150 \mu \mathrm{g} / \mathrm{mL})$ were impregnated into each well and antibiotic chloramphenicol $(0.1 \%)$ and deionised water were used as positive and negative control, respectively. After 24 hours incubation at $37^{\circ} \mathrm{C}$ zone of inhibition was measured in millimetres, was recorded as mean $\pm \mathrm{SD}$ of the triplicates experiments.

\section{Statistical analysis}

All the experiments were conducted in triplicates and results were expressed as mean \pm standard deviation (SD). Student's t-test and one-way analysis of variance (ANOVA) were applied to ascertain significant differences in antibacterial activity using Sigma Stat software, version 2. Differences were considered to be statistically significant at $\mathrm{p}<0.05$.

\section{RESULTS AND DISCUSSION}

\section{UV-vis absorption analysis}

The biosynthetic methods have been investigated as an alternative to chemical and physical ones. In this regard, marine plant $M$. wightiana proves to be an important biological component for extracellular biosynthesis of stable AgNPs. It was observed that the reduction of the $\mathrm{Ag}^{+}$ions during the exposure to $M$. wightiana filtrate can be easily followed by visual observation and UV-vis spectroscopy. It was well known that AgNPs shows a yellowish brown color in aqueous solution; this color arises from excitation of surface plasmon vibrations in the metal nanoparticles $\left[{ }^{16}\right]$.Reduction of $\mathrm{AgNO}_{3}$ was visually evident from the colour change of reaction mixture after $10 \mathrm{~min}$ of reaction (Fig.1). The UV-Vis absorption spectra recorded from the resulting solutions showed the characteristic surface plasmon resonance (SPR) band of Ag nanoparticles at around $434 \mathrm{~nm}$ (Fig. 2). It was observed from the spectra that the SPR band of AgNPs was steadily increased in intensity as a function of time of reaction. Nanoparticle size also evidenced by the colour of the solution as smaller the size of Ag NPs and greater 
Phytofabrication of silver nanoparticles using Myriostachya wightiana as a novel bioresource, and evaluation of their biological activities

the colours shift towards red $\left[{ }^{17}\right]$. Our results are similar to the SPR with characteristic peaks of AgNPs prepared by [ $\left.{ }^{18,19,20}\right]$.

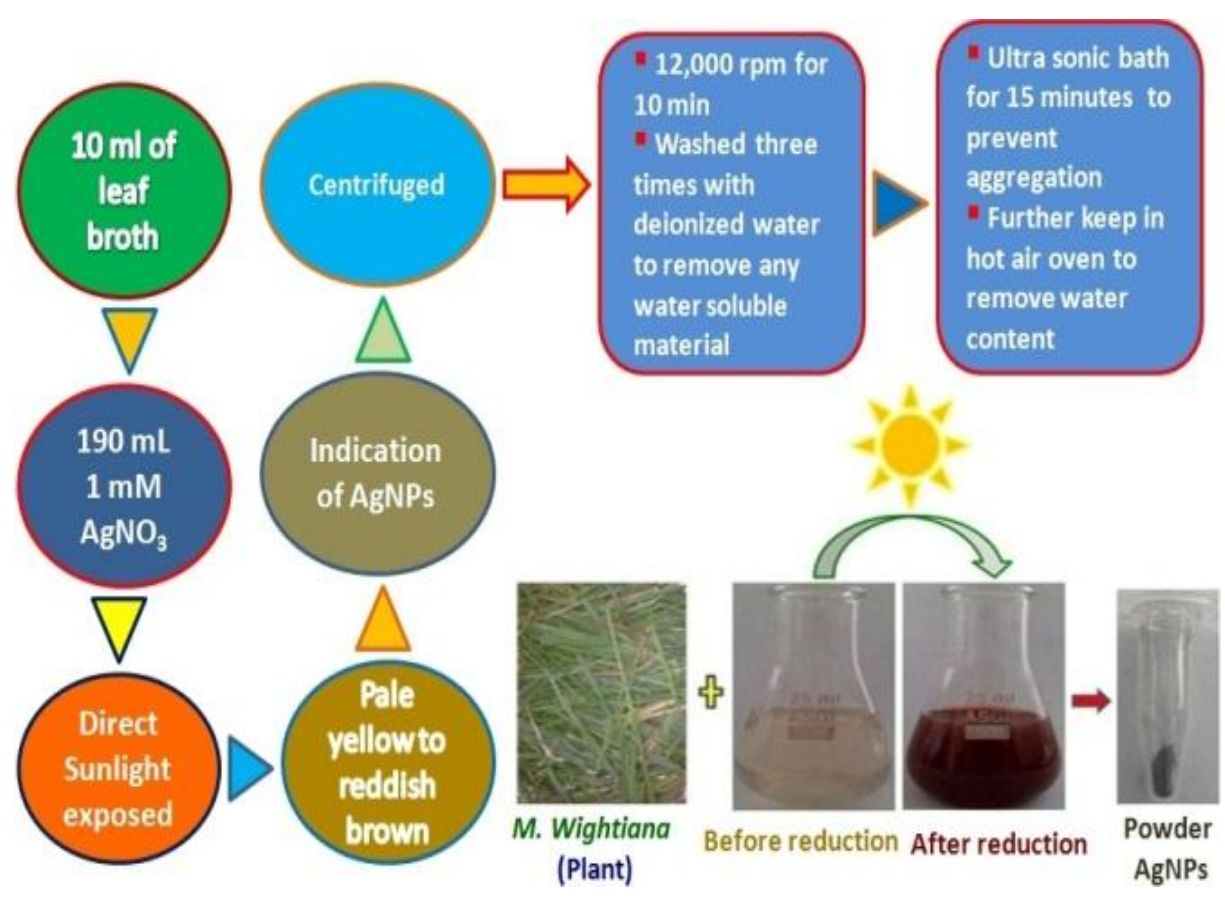

Figure. 1- Schematic diagram of biosynthesis and purification of AgNPs

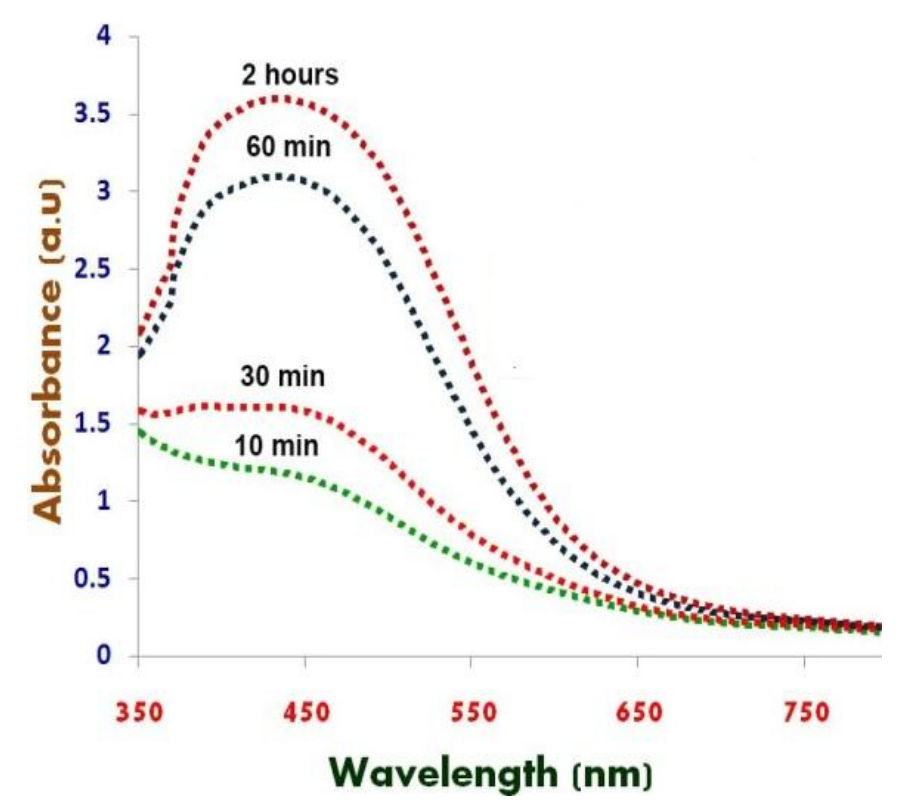

Figure.2- UV-vis absorption spectra of colloidal AgNPs synthesized using plant M. wightiana.

\section{Zeta potential and DLS analysis}

Zeta potential determines the particle size distribution,charge on the particle and the stability of colloidal nanoparticles, where as DLS measures hydrodynamic size of the hydrosol (particle suspension). The Zeta potential of AgNPs was shown with particles carrying a charge of $-28.9 \mathrm{mV}$ (Fig. 3a) and DLS size is $75 \mathrm{~nm}$ (Fig.3b) 
respectively. Zeta potential value was strongly negative which clearly indicates that particles have good colloidal nature.

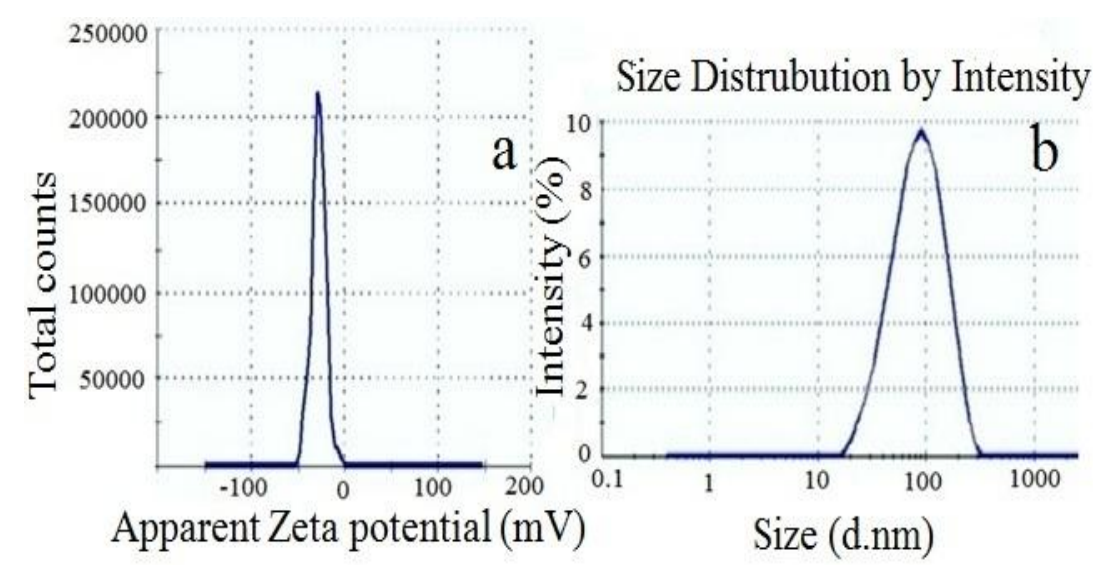

Figure 3- (a) Zeta potential and (b) Dynamic light scattering

\section{Morphology and size by Transmission electron microscope}

TEM was employed to visualize the size and shape of Ag nanoparticles. TEM images at different magnifications elucidated that AgNPs from M. wightiana leaf extract were polydisperse with irregular shape and size varied from $15-65 \mathrm{~nm}$ (Fig. $4 \mathrm{a}$ and $\mathrm{b}$ ). In TEM analysis a single drop of sample is placed on carbon film and that does not fully represent the entire solution and while acquiring the image, the localized heat generated by the electron beam somewhat alters the arrangement of the nanoparticles TEM analysis of images obtained several times evidenced that particle sizes are varied. Analysis of particle size with TEM and DLS suggested different sizes this variation occurred because DLS analysis includes the ligand shell and determines the hydrodynamic size, where as in TEM look at only metallic core $\left[{ }^{21}\right]$.

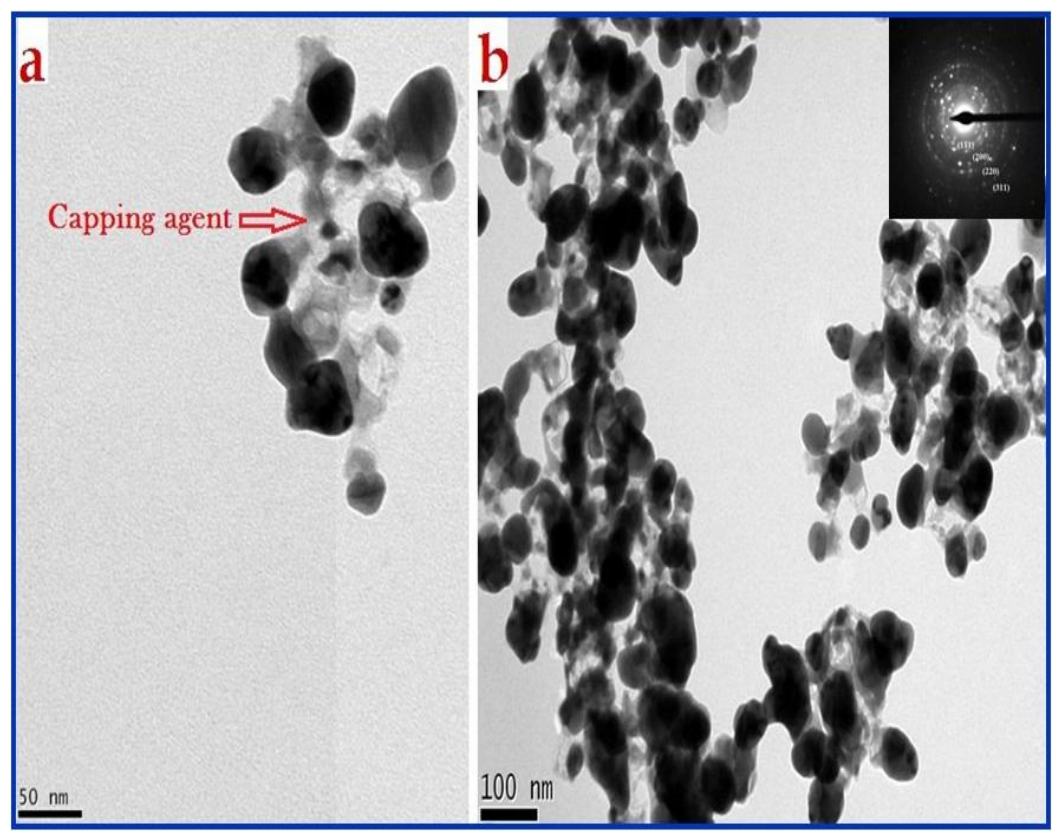

Figure 4-TEM micrographs of AgNPs at different magnifications (a) $50 \mathrm{~nm}$ (b) $100 \mathrm{~nm}$ 
Phytofabrication of silver nanoparticles using Myriostachya wightiana as a novel bioresource, and evaluation of their biological activities

\section{Fourier transform infrared spectroscopy (FT-IR) analysis}

FTIR spectrum (Fig. $5 \mathrm{a}, \mathrm{b}$ ) of the M. wightiana leaf extract and synthesized $\mathrm{Ag}$ nanoparticles was carried out to identify the possible/biomolecules responsible for capping and efficient stabilization of the metal nanoparticles synthesized by leaf broth The peak IR bands observed at $3422.37 \mathrm{~cm}^{-1}$ and $3413.69 \mathrm{~cm}^{-1}$ corresponds to $\mathrm{N}-\mathrm{H}$ stretching groups of $1^{\circ}, 2^{\circ}$ amines and amides. Other peaks of $M$. wightiana leaf extract at $2930.62 \mathrm{~cm}^{-1}$ and $2852.70 \mathrm{~cm}^{-1}$ represent C-H stretch of alkanes. The peaks at $1649.25 \mathrm{~cm}^{-1}, 1462.55 \mathrm{~cm}^{-1}, 1265.73 \mathrm{~cm}^{-1}$ assigned to N-H bend $1^{\circ}$ amines, $\mathrm{C}-\mathrm{H}$ bend, alkanes and $\mathrm{C}-\mathrm{O}$ Alcohols, Ethers, Carboxylic acids, Ester. The band at 752.30 and $541.83 \mathrm{~cm}^{-1}$ are very weak bands (Fig $5 \mathrm{a}$ ). In the case of nanoparticles, a large shift in the absorbance peak with decreased band intensity was observed at $2920.74 \mathrm{~cm}^{-1}$ and $2852.70 \mathrm{~cm}^{-1}$ represents $\mathrm{C}-\mathrm{H}$ stretch of alkanes (Fig 5 b). The spectra also illustrate a prominent shift in the wave numbers corresponding to $1629.70 \mathrm{~cm}^{-1}$ and $1440.38 \mathrm{~cm}^{-1}$ assigned to $\mathrm{N}-\mathrm{H}$ bend $1^{\circ}$ amines and C-C stretching arises due to aromatics. The band at $599.24 \mathrm{~cm}^{-1}$ and 466.03 $\mathrm{cm}^{-1}$ are very weak bands. The dual role of the plant extract as a reducing and capping agent and presence of some functional groups was confirmed by FTIR analysis of AgNPs. FT-IR reveals that amine and amide groups may be involved in the reduction and stabilizing mechanism. The results are in good agreement with those found in literature $\left[{ }^{22}\right]$.

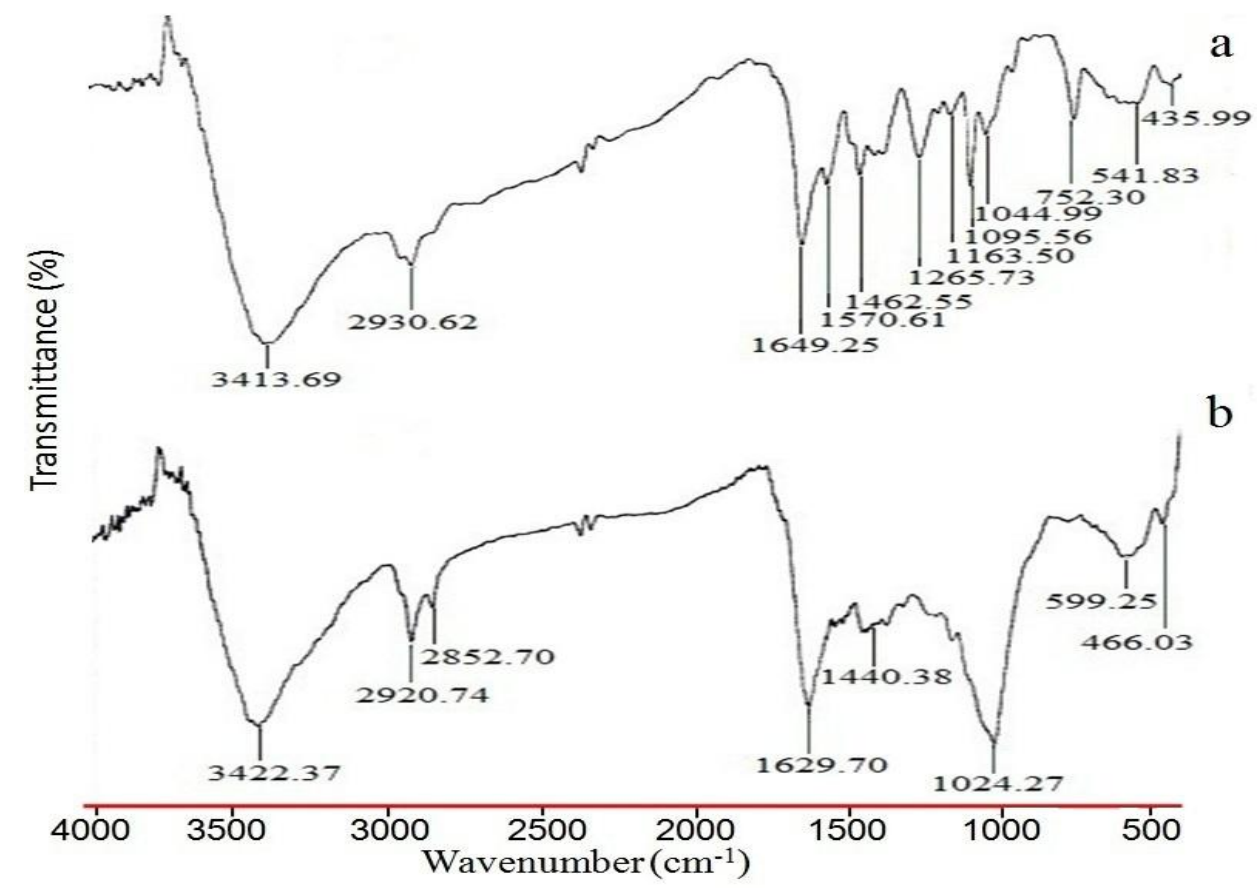

Figure 5- (a) FTIR spectrum of (a) $M$. wightiana aqueous extract (b) AgNPs synthesized by using $M$. wightiana extract.

\section{XPS of the silver nanoparticles}

XPS is a surface-sensitive analytical tool that is used to investigate the chemical environment of the outermost surface layer of NPs up to few nanometres and also to know their oxidation states. (Fig. 6) exhibits the XPS results of the obtained AgNPs. The overall spectrum indicates the presence of strong $\mathrm{C} 1 \mathrm{~s}, \mathrm{O} 1 \mathrm{~s}, \mathrm{~N} 1 \mathrm{~s}$, and Ag 3d core levels. The peak (Fig. 6 a) at $284.6 \mathrm{eV}$ can be attributed to C-C and C-H. Carbon bound to nitrogen $(\mathrm{C}-\mathrm{O}$ and $\mathrm{C}-\mathrm{N})$ and hydroxyl groups $(\mathrm{C}-\mathrm{OH})$ and $\mathrm{O}-\mathrm{C}=\mathrm{O}$ / $\mathrm{O}-\mathrm{C}=\mathrm{N}$ are located at $285.9,287.1$ and $288.6 \mathrm{eV}$ corresponds to the carbon 
contribution from the phenyl rings of the protein $\left[{ }^{23}\right]$. The $\mathrm{O}$ 1s (Fig. $6 \mathrm{~b}$ ) core level assigned at 531.9 and $533.6 \mathrm{eV}$ can be ascribed to the $(\mathrm{C}=\mathrm{O})$ bond which can be assigned to the unprotonated and protonated amine /amide species, respectively present in protein molecules. The $\mathrm{N} 1 \mathrm{~s}$ (Fig. $6 \mathrm{c}$ ) peak located at $400.4 \mathrm{eV}$ could be assigned to neutral amino group $-\mathrm{NH} 2$ or $\mathrm{N}-\mathrm{H}$ bond of amide bond present in the protein moiety $\left[{ }^{24,25,26}\right.$. From the survey scan (Fig.6d) and spectrum of $\mathrm{Ag} 3 \mathrm{~d}$ (Fig. 6 e) the binding energies of $\mathrm{Ag} 3 \mathrm{~d} 5 / 2$ and $\mathrm{Ag} 3 \mathrm{~d} 3 / 2$ are found to be at 368 and $374 \mathrm{eV}$, respectively $\left[{ }^{27,28,29,30}\right]$. Therefore, it is concluded that the proteins were responsible for the bio-reduction of $\mathrm{AgNO} 3$ into AgNPs.
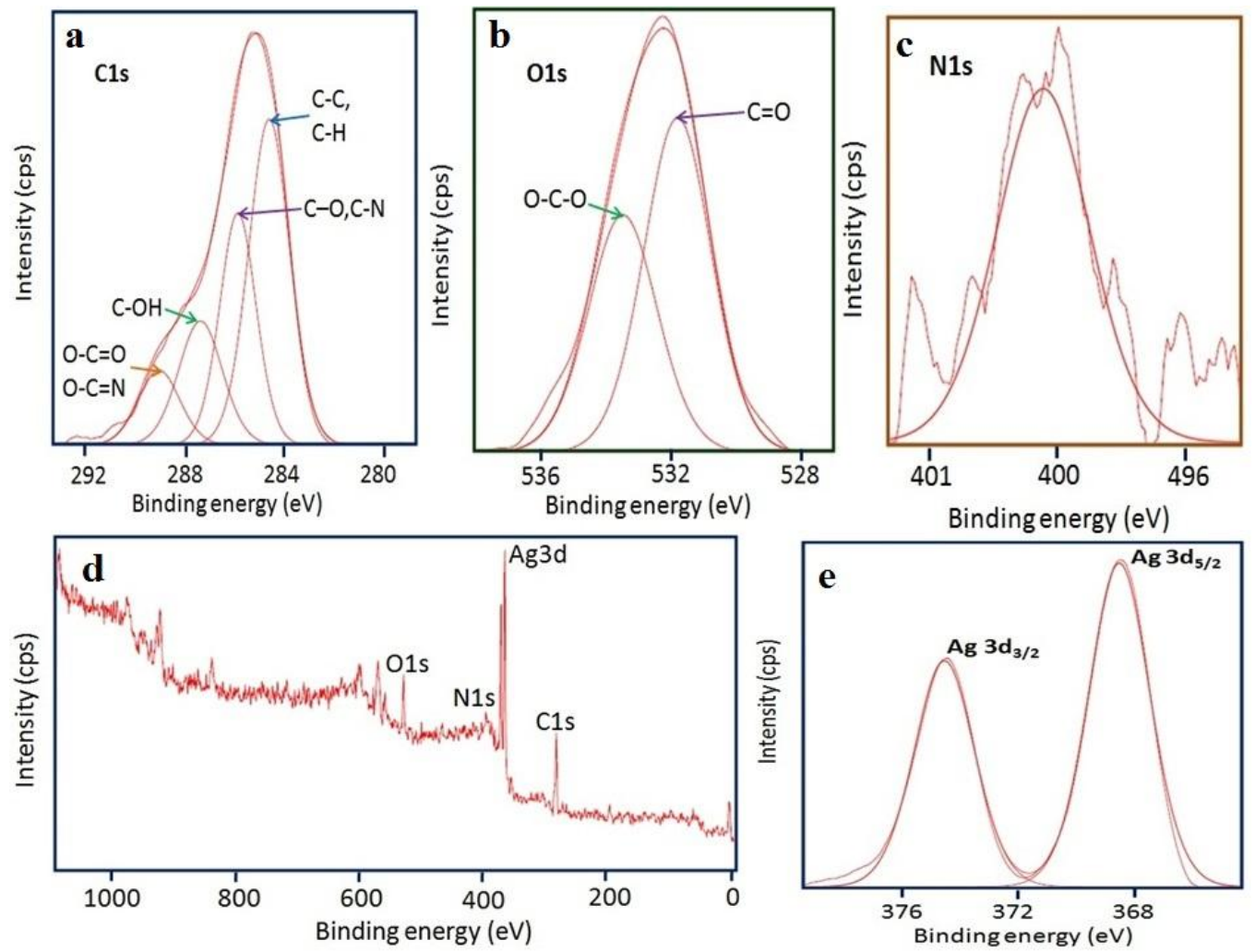

Figure. 6- High resolution XPS spectra of Ag NPs synthesized by using M. wightiana extract (a) C 1s, (b) O1s (c) N 1s (d) Survey scan and (e) Ag 3d.

\section{X-ray diffraction analysis}

$\mathrm{X}$-ray diffraction is used to assess the crystalline structure and preferred orientation in powder solid samples of the AgNPs. The X-ray diffraction (XRD) spectra of the silver nanoparticles showed four main characteristic Bragg's diffraction peaks. The peaks were positioned at $2 \theta$ of $38.51^{\circ}, 44.35^{\circ}, 64.20^{\circ}$ and $77.44^{\circ}$. All these reflections corresponded to (111) (200) (222) and (311) facets of the face centered cubic (fcc) structure of silver nanoparticles synthesized by aqueous extract of $M$. wightiana plant. The diffraction peaks were consistent with standard database files (JCPDS card No 04-0783), indicating that the synthesized nanoparticles were of pure crystalline nature.

\section{Contact toxicity against stored grain pests}

The results (Table.1) indicate that at $50 \mu \mathrm{g}$ conc mortality of T. castaneum, $R$. dominica and $S$. oryzae were $20.3 \pm 0.22,32.8 \pm 0.32,29 \pm 0.45$ respectively with biogenic silver treatment. Whereas, synthetic silver treatment at same concentration, lower mortality was observed in comparison to control. Biogenic 
Phytofabrication of silver nanoparticles using Myriostachya wightiana as a novel bioresource, and evaluation of their biological activities

silver treatment at $100 \mu \mathrm{g}$ concentration, maximum value of mortality against $R$. dominica was noted followed by $T$. castaneum $(39.2 \pm 0.24)$ and $S$. oryzae (33.2 \pm 0.38$)$. At the highest concentration of $(150 \mu \mathrm{g})$ biogenic silver treatment was found to be comparatively toxic and killed $55.2 \%$ of $T$. castaneum, $52.8 \pm 0.24 \%$ of $R$. dominica and $47.4 \pm 0.16$ of $S$. oryzae insects after $24 \mathrm{hrs}$. It was clear from the results that synthetic silver treatment was not significantly effective in causing mortality against all the treated insects' viz. T. castaneum, R. dominica and $S$. oryzae indicated that the biogenic silver was found to be remarkably more potent than the synthetic silver nano particles. Hence the most toxic sample was biogenic silver nano particles and the least toxic was synthetic silver nanoparticles compared to control. The use of nanoparticles in pest control is still at early stage and in recent years, nanoparticles have received much attention for controlling of stored insect pests $\left[{ }^{31}\right]$. But in our study moderate toxic effects were observed with biogenic AgNPs on stored insect pests $T$. castaneum, $R$. dominica and $S$. oryzae adults; this is due to the thickness of the cuticle, lower dose and low penetrability of nanoparticles.

Table 1-Contact toxicity of the biosynthesized and synthetic nano silver against stored grain pests.

\begin{tabular}{|c|c|c|c|c|}
\hline $\begin{array}{c}\text { AgNPs } \\
\text { material } \\
\text { type }\end{array}$ & $\begin{array}{c}\text { Dose } \\
\left(\mu \mathrm{g} / \mathrm{cm}^{2}\right)\end{array}$ & $\begin{array}{c}T . \\
\text { casutanem }\end{array}$ & $\begin{array}{c}R . \\
\text { dominica }\end{array}$ & S. oryzae \\
\hline \multirow{3}{*}{ Biogenic } & 50 & $20.3 \pm 0.22$ & $32.8 \pm 0.32$ & $29 \pm 0.45$ \\
\hline & 100 & $40.2 \pm 0.34$ & $44.2 \pm 0.24$ & $30.2 \pm 0.38$ \\
\hline & 150 & $55.2 \pm 0.14$ & $52.8 \pm 0.24$ & $47.4 \pm 0.16$ \\
\hline Synthetic & - & $4.2 \pm 00$ & $3.1 \pm 0.26$ & $2.1 \pm 0.26$ \\
\hline
\end{tabular}

Values are mean \pm Standard error (ANOVA followed by TUKEY test performed, $\mathrm{P}<0.001$

\section{Antibacterial activities}

In the present study, the antibacterial activity of AgNPs obtained by M. wightiana were tested against $X$. campestris and $R$. solanacearum at various concentrations ranging from 25-150 $\mu \mathrm{g} / \mathrm{mL}$ (Fig.7a and b). The results of showed that antimicrobial activity with maximum a zone of inhibition was found in $X$. campestris $(17 \pm 0.33 \mathrm{~mm})$, followed by $R$. solanacearum $(11 \pm 0.17 \mathrm{~mm})$ at 150 $\mu \mathrm{g} / \mathrm{mL}$ concentration of AgNPs. The lowest zone of inhibition was observed with $X$. campestris $(9.2 \pm 0.26 \mathrm{~mm})$ and no zone was observed with $R$. solanacearum at $25 \mu \mathrm{g} / \mathrm{mL}$. The reference antibiotic, Chloramphenicol showed variable inhibitory activity against tested bacteria (Table.2).

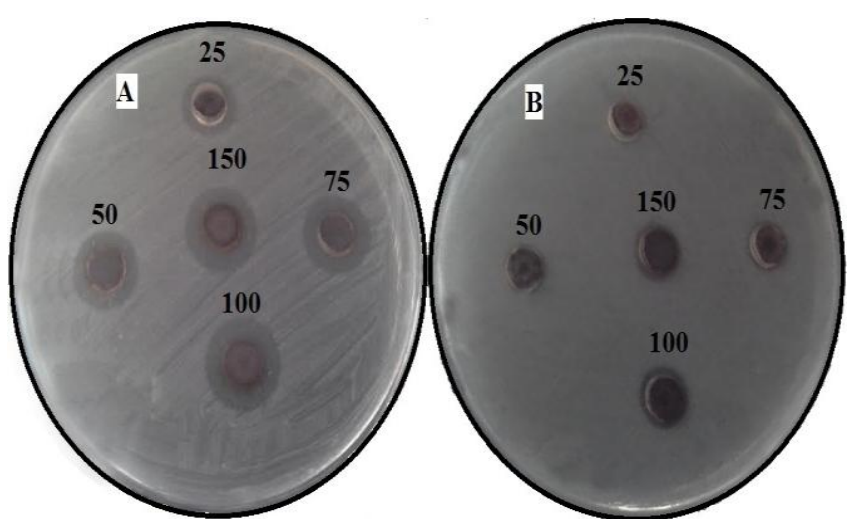

Figure. 7- Zone of inhibition of biosynthesized AgNPs at different concentrations $(25,50,75100$ and $150 \mu \mathrm{g} / \mathrm{ml})$ against (a) $X$. campestris (b) $R$. solanacearum 
Table.2 - In vitro extract antibacterial potential of biosynthesised AgNPs using M. wightiana leaf

\begin{tabular}{ccc}
\hline $\begin{array}{c}\text { AgNPs } \\
\text { conc. }(\boldsymbol{\mu g} / \\
\mathbf{m l})\end{array}$ & \multicolumn{2}{c}{ Zone of inhibition in $(\mathbf{m m})$} \\
\cline { 2 - 3 } & $\boldsymbol{X}$. campestris & $\boldsymbol{R}$. solanacearum \\
\hline 25 & $9.2 \pm 0.26$ & --- \\
50 & $11.6 \pm 0.34$ & $7.9 \pm 0.11$ \\
75 & $12.4 \pm 0.45$ & $8.8 \pm 0.11$ \\
100 & $14 \pm 0.15$ & $10.2 \pm 0.15$ \\
150 & $17 \pm 0.33$ & $11 \pm 0.17$ \\
Positive & $26.7 \pm 0.37$ & $20.7 \pm 0.7$ \\
control &
\end{tabular}

Values \pm SD indicates the replicates of three experiments $(n=3)$

Now-a-day, microbial pest management is very important and tough task because pathogens are developing resistance to synthetic chemicals. Today it has become important to increase crop production to feed the growing world population. To meet this increasing demand of food, researchers are trying to develop an efficient and ecofriendly technology based on the innovative techniques like green nanobiotechnogy to manage diseases of plants. The present study demonstrated that $X$. campestries is more susceptible than $R$. solanacearum towards AgNPs obtained by $M$. wightiana at all concentrations. Irrespective of the microbes tested, zone of inhibition increased with increased concentration of Ag NPs in a concentration dependent manner. Similarly, $\left[{ }^{15}\right]$ have reported dose dependant inhibition by $\mathrm{Ag}$ NPs synthesized by Leptadenia reticulata leaf aqueous extracts. This difference may be due to the susceptibility of the organism used in the current study. Development of resistance to silver in microbes is improbable due to its action on a broad spectrum of targets in the cell $\left.{ }^{32}\right]$. Metal nanoparticles are harmful to bacteria $\left[{ }^{33}\right]$.The antimicrobial activities of AgNPs are influenced by the dimensions of the particles $\left[{ }^{34}\right]$.mainly like shape $\left[{ }^{35}\right]$ and size $\left[{ }^{36}\right]$.The high bactericidal activity of silver nanoparticles is due to their extremely large surface area, which provides better contact with microorganisms. There are several explanations by scientists but the exact mechanism of action of AgNP is unknown. The nanoparticles get attached to the cell membrane and also penetrate inside and preferably attack the respiratory chain, cell division finally leading to cell death. The present study also proved that M. wightiana mediated AgNPs have strong antibacterial agents against phytopathogens.

\section{CONCLUSION}

To the best of our knowledge the present study was successfully produced AgNPs using aqueous leaf extract of $M$. wightiana under direct sunlight exposure method for the first time. This present method is facile, cost effective, clean and green, and therefore is applicable for a variety of purposes. Moreover, it is easy to scale up the production of AgNPs to industrial scale using this method.The potential uses and benefits of nanotechnology are enormous including agriculture and this kind of study may also create platform in future for preparing nanopesticides against stored pests and resistant phytopathogens. The present study revealed $M$. wightiana mediated AgNPs showed significant antibacterial activity against and stored pests hence this salt marsh grass can be a future vision for the discovery of novel alternative to chemical pesticides and antibiotics. 
Phytofabrication of silver nanoparticles using Myriostachya wightiana as a novel bioresource, and evaluation of their biological activities

\section{ACKNOWLEDGMENTS}

The authors would like to thank Director, CSIR-IICT, Hyderabad for providing the facilities and support.

\section{REFERENCES}

1. Paul K, Bag BG, Samanta K. Green coconut (Cocos nucifera Linn.) shell extract mediated size controlled green synthesis of polyshaped gold nanoparticles and its application in catalysis. Appl Nanosci. 2014; 4: 769-775.

2. Nair LS, Laurencin CT. Silver nanoparticles: synthesis and therapeutic applications. $J$ Biomed Nanotechnol. 2007; 3: 301-316.

3. Lee KS, El-Sayed M. Gold and silver nanoparticles in sensing and imaging: sensitivity of plasmon response to size, shape, and metal composition. J Phys Chem. B. 2006; 110 (39): 19220-19225.

4. Jain PK, Huang X, El-Sayed IH, EL-Sayed MA. Noble metals on the nanoscale: optical and photothermal properties and someapplications in imaging, sensing,biology, and medicine. Acc Chem Res. 2008; 41 (12): 1578-1586.

5. Kagithoju S, Godishala V, Nanna RS. Eco-friendly and green synthesis of silver nanoparticles using leaf extract of Strychnos potatorum Linn.F. and their bactericidal activities. 3 Biotech. 2015; 5(5): 709-714

6. Das VL, Thomas R, Varghese RT, Soniya EV, Mathew J, Radhakrishnan EK . Extracellular synthesis of silver nanoparticles by the Bacillus strain CS 11 isolated from industrialized area. 3 Biotech. 2014; 4: 121-126.

7. Metuku RP, Pabba S, Burra S, Bindu SVSSSLNH, Gudikandula K, Charya MAS. Biosynthesis of silver nanoparticles from Schizophyllum radiatum HE 863742.1: their characterization and antimicrobial activity. 3 Biotech. 2014; 4: 227-234.

8. Maiti S, Krishnan D, Barman G, Ghosh SK, Laha JK.Antimicrobial activities of silver nanoparticles synthesized from Lycopersicon esculentum extract. J Anal Sci Technol. 2014; 5: 40 .

9. Sathish kumar M, Pavagadhi S, Mahadevan A, Balasubramanian R. Biosynthesis of gold nanoparticles and related cytotoxicity evaluation using A549cells. Ecotoxicol Environ Saf. 2015; 114:232-240.

10. Govindraju K, Kiruthiga V, Singaravelu G. Evaluation of biosynthesized silver nanoparticles against fungal pathogens of mulberry Morus indica. J Biopesticid. 2008; 1: 101-104.

11. Khalil MMH, Ismail EH, El-Baghdady KZ, Mohamed D . Green synthesis of silver nanoparticles using olive leaf extract and its antibacterial activity. Arabian J Chem. 2014; 7 (6): 1131-1139.

12. Vadlapudi V, Naidu KC. In vitro antimicrobial potentiality of mangrove plant Myriostachya wigtiana against selected phytopathogens. Biomed \& Pharmacol J. 2009; 2 (2): 235-238.

13. Abo-elyousr KAM, Asran MR . Antibacterial activity of certain plant extracts against bacterial wilt of tomato. Archives of Phytopathology and Plant Protection. 2009; 42 (6): 573-578.

14. Kim SI, Park C, Ohh MH, Cho HC, Ahn YJ. Contact and fumigant activities of aromatic plant extracts and essential oils against Lasioderma serricorne (Coleoptera: Anobiidae), J Stored Prod Res. 2003; 39: 11-19.

15. Kumara Swamy M, Sudipta KM, Jayanta K, Balasubramanya S.The green synthesis, characterization, and evaluation of the biological activities of silver nanoparticles synthesized from Leptadenia reticulata leaf extract. Appl Nanosci. 2015; 5: 73-81.

16. Fayaz AM, Balaji K, Girilal M, Yadav R, Kalaichelvan PT, Venketesan R .Biogenic synthesis of silver nanoparticles and their synergistic effect with antibiotics: a study against gram-positive and gram-negative bacteria. Nanomed Nanotechnol Biol Med. 2010; 6: 103109. 
17. Mock JJ, Barbic M, Smith DR, Shultz DA, Shultz S. Shape effect in plasmon resonance of individual colloidal silver nanoparticles. Journal of Chemistry and Physics 2002; 116: 6755-6759.

18. Preetha Devaraj, Prachi Kumari, Chirom Aarti, Arun Renganathan. Synthesis and characterization of silver nanoparticles Using Cannonball leaves and their Cytotoxic Activity against MCF-7 Cell Line, Journal of Nanotechnology 2013; Article ID 598328, 5 pages, http://dx.doi.org/10.1155/2013/598328,

19. Gavade NL, Kadam AN, Suwarnkar MB, Ghodake VP, Garadkar KMBiogenic synthesis of multi-applicative silver nanoparticles by using Ziziphus Jujuba leaf extract. Spectrochim Acta A Mol Biomol Spectrosc. 2015; 136; 953-960.

20. Kiran Jadhav, Dinesh Dhamecha, Bhagyashree Dalvi, Mrityunjaya Patil. Green Synthesis of Silver Nanoparticles Using Salacia chinensis: Characterization and its Antibacterial Activity. Particulate Science and Technology. 2015; 33(5): 445-455.

21. Kasture MB, Patel P, Prabhune AA, Ramana CV, Kulkarni AA, Prasad BLV. Synthesis of silver nanoparticles by sophorolipids: Effect of temperature and sophorolipid structure on the size of particles. J Chem Sci. 2008; 120 (6): 515-520.

22. Vanaja M, Paulkumar K, Gnanajobitha G, Rajeshkumar S, Malarkodi C, Annadurai G. Herbal Plant Synthesis of Antibacterial Silver Nanoparticles by Solanum trilobatum and Its Characterization. International Journal of Metals , 2014; Article ID 692461, 8 pages

23. Sujoy K. Das, Calum Dickinson, Fathima Lafir, Dermot F. Brougham, Enrico Marsili. Synthesis, characterization and catalytic activity of gold nanoparticles biosynthesized with Rhizopus oryzae protein extract. Green Chem. 2012; 14: 1322-1334.

24. Kristopher A. Kilian, Till Böcking, Katharina Gaus, Michael Gal, J. Justin Gooding. Peptide-Modified Optical Filters for Detecting Protease Activity. ACS nano. 2007;1(4): 355-361.

25. Zhang L, Chatterjee A, Ebrahimi M, Leunga KT, Hydrogen-bond mediated transitional adlayer of glycine on $\mathrm{Si}(111), 7 \mathrm{X} 7$ at room temperature, The journal of chemical physics. 2009; 130: 121103.

26. Saengrawee Sriwichai, Sumarin Niroj, Sukon Phanichphant. Fabrication and Characterization of Cytochrome C Modified Poly(3-Aminobenzoic Acid) Thin Film. Molecular Crystals and Liquid Crystals, 2015; 621:1, 142-149.

27. Sumesh E, Bootharaju MS, Pradeep AT . A practical silver nanoparticle-based adsorbent for the removal of $\mathrm{Hg} 2$ from water. J Hazard Mater. 2011; 189:450

28. Lai Y, Zhang H, Xie K, Gong D, Tang Y, Sun L, Lin C, Chen Z. Fabrication of uniform $\mathrm{Ag} / \mathrm{TiO} 2$ nanotube array structures with enhanced photoelectrochemical performance. New J Chem. 2010; 34:1335-1340.

29. Bipinchandra K. Salunke, Shailesh S. Sawant, Tae Koo Kang,Deok Yun Seo, Youngjong Cha, Sun A.Moon, Bassam Alkotaini,Ezhaveni Sathiyamoorthi, Beom Soo Kim. Potential of Biosynthesized Silver Nanoparticles as Nanocatalyst for Enhanced Degradation of Cellulose by Cellulase, Journal of Nanomaterials, Volume 2015; Article ID 289410, 8 pages: http://dx.doi.org/10.1155/2015/289410.

30. Premanand G, N. Shanmugam N, Kannadasan N, Sathishkumar K, Viruthagir G. Nelumbo nucifera leaf extract mediated synthesis of silver nanoparticles and their antimicrobial properties against some human pathogens. Appl Nanosci. 2016; 6:409-415

31. Vani C, Brindhaa U. Silica nanoparticles as nanocides against Corcyra cephalonica (S.), the stored grain pest. Int J Pharm Bio Sci. 2013; 4(3): 1108 - 1118.

32. Inoue Y, Hoshino M, Takahashi H, Noguchi T, Murata T, Kanzaki Y.Bactericidal activity of Ag-zeolite mediated by reactive oxygen species under aerated conditions. J Inorg Biochem. 2002; 92: 37-42.

33. Chwalibog A, Sawosz E, Hotowy A, Szeliga J, Mitura S, Mitura K, Grodzik M, Orlowski P, Sokolowska A . Visualization of interaction between inorganic nanoparticles and bacteria or fungi. Int J Nanomed. 2015; 5: 1085-1094.

34. Kaviya S, Santhanalakshmi J, Viswanathan B . Green synthesis of silvernanoparticles using Polyalthia longifolia leaf extract along with d-sorbitol: studyof antibacterial activity. $J$ Nanotechnol. 2011; Article ID 152970, 5 pages. DOI: 10.1155/2011/152970.

35. Monteiro DR, Gorup LF, Takamiya AS, Ruvollo-Filho AC, de Camargo ER, Barbosa DB. The growing importance of materials that prevent microbial adhesion: Antimicrobial effect of medical devices containing silver. Int J Antimicrob Agents 2009; 334 (2): 103-110. 
Phytofabrication of silver nanoparticles using Myriostachya wightiana as a novel bioresource, and evaluation of their biological activities

36. Kvitek L, Panacek A, Soukupova J, Kolar M, Vecerova R, Prucek R, Holecova M, Zboril R. Effect of surfactants and polymers on stability and antibacterialactivity of silver nanoparticles (Nps). J Phys Chem. 2008; 112 (15): 5825-5834.

Received: February 03, 2016; Accepted: July 14, 2016 